\title{
Colorectal cancer survival: Results from a hospital-based cancer registry
}

\author{
Fernando Agüero ${ }^{1,2}$, Cristiane Murta-Nascimento ${ }^{1,3,4}$, Manuel Gallén $^{5}$, Montserrat Andreu-García ${ }^{6}$, \\ Miguel Pera ${ }^{7}$, Cristina Hernández ${ }^{1}$, Andrea Burón ${ }^{1,3}$ and Francesc Macià ${ }^{1,3,4}$
}

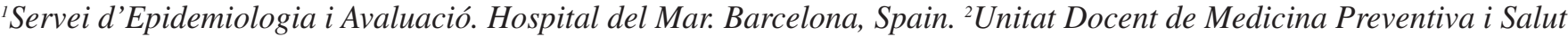
Pública. Hospital del Mar-UPF-ASPB. Barcelona, Spain. ${ }^{3}$ Grup de Recerca en Epidemiologia i Avaluació. IMIM (Institut de Recerca Hospital del Mar). Barcelona, Spain. ${ }^{4}$ Red de Investigación en Servicios de Salud en Enfermedades Crónicas (REDISSEC). Spain. ${ }^{5}$ Servei d'Oncologia, ${ }^{6}$ Servei de Digestologia and ${ }^{7}$ Servei de Cirurgia General. Hospital del Mar. Barcelona, Spain

\section{ABSTRACT}

Introduction: colorectal cancer is one of the most common malignancies in developed countries. Data on specific and 10-year survival are scarce. This study analyzes overall and disease-specific survival for patients with colorectal cancer and assesses the value of clinical factors on disease-specific survival.

Methods: a retrospective cohort study of newly diagnosed invasive colorectal cancer cases diagnosed from 1992 to 2007 were identified through the Hospital del Mar Cancer Registry. Five- and 10-year survival functions were estimated using Kaplan-Meier method. Cox proportional hazard models were used to assess prognostic factors.

Results: a total of 2,080 patients with colorectal cancer were identified. The median age at diagnosis was 72 years and $58.5 \%$ were men. By the end of the follow-up period (December 2008), 1,225 patients had died and $68.4 \%$ of deaths were due to colorectal cancer. The 5- and 10-year cancer-specific survival rates were 55.5\% (95\%CI 53.9-57.9\%) and 48.5\% (95\%CI 45.6-51.3\%), respectively. The 5-year specific survival rate improved in the last period (20032007) (60.4\%, 95\%CI 55.4-65.0) compared with 1992-1997 (53.4\%; 95\%CI 49.2-57.4) and 1998-2002 (52.0\%; 95\%CI 47.856.2). Various factors were independently associated with excess CRC mortality: male sex (HR 1.21), age at diagnosis $>75$ years (HR 1.97), rectal location (HR 1.33), more advanced stages (stage IV: HR 18.54), poorly differentiated/undifferentiated tumors (HR 1.80), and admission through the emergency department (HR 1.52).

Conclusions: cancer-specific survival improved from 1992 to 2007. This improvement could be due to more effective treatment, since changes in stage distribution or age at diagnosis were not observed during the study period. Overall survival rates should notably improve with the implementation of a population-based colorectal cancer screening program in Spain.

Key words: Colorectal neoplasms. Survival analysis. Prognosis. Hospitals. Registries.

Received: $13-04-2012$

Accepted: $30-10-2012$

Correspondence: Francesc Macià. Hospital del Mar - Parc de Salut Mar. Passeig Maritim, 25-29. 08003 Barcelona, Spain.

e-mail: fmacia@parcdesalutmar.cat

\section{INTRODUCTION}

Colorectal cancer (CRC) is one of the most common cancers in developed countries. Incidence rates are high in Europe and, within Europe, are particularly high in Catalonia. CRC was the most common cancer from 1998 to 2002 and its incidence is estimated to have an upward trend in the present decade (1). The prognosis of CRC is relatively good in terms of survival, which varies markedly across European countries (2). In Europe and Catalonia (3), survival in CRC patients has increased. In Catalonia (3), the 5-year relative survival rate was $42.7 \%$ (95\% CI 38-48) in 1985-1989 and 52.9\% (95\% IC 49-57) in 1995-1999. Several publications have observed an independent prognostic effect of factors such as age at diagnosis (4), sex $(4,5)$, stage at diagnosis (6), histological grade (4), anatomical location $(4,5)$, type of treatment received $(7)$, degree of co-morbidity (8), and type of hospital admission (9).

Population-based cancer registries have been the information source for many of the above-mentioned studies and are an essential tool to characterize this malignancy. However, the information on tumor features provided by these registries is sometimes limited and data on the 10year survival rate are scarce. In contrast, hospital-based cancer registries complement this information, usually providing more detailed data, which allows specific mortality to be estimated and/or the prognostic value of clinical variables to be investigated.

The Cancer Registry of Hospital del Mar (Barcelona) is one of the best established hospital-based cancer registries in Spain, with comprehensive clinical data and extensive follow-up (9). The aim of this study was to calculate the

Agüero F, Murta-Nascimento C, Gallén M, Andreu-García M, Pera M, Hernández C, Burón A, Macià F. Colorectal cancer survival: results from a hospital-based cancer registry. Rev Esp Enferm Dig 2012;104:572-577. 
5- and 10-year survival rates for patients with newly diagnosed CRC and to assess the prognostic value of clinical factors.

\section{METHODS}

\section{Data source}

This study was based on the information collected by the Cancer Registry of Hospital del Mar. This public general teaching hospital serves a population of approximately 300,000 inhabitants living in two of the 10 municipal districts of Barcelona (Catalonia, Spain). The cancer registry approach has been described in detail elsewhere (9). Briefly, this registry collects data on all cancer cases diagnosed and/or treated at Hospital del Mar. In this database, cancers are coded according to the International Classification of Diseases for Oncology, $1^{\text {st }}$ edition (ICD-O-1). The followup information is updated automatically at each patient visit or if patients are admitted to the hospital. Information on the date and cause of death are obtained annually through a record linkage procedure between the hospital registry and the Catalonian Mortality Registry.

Patients with newly diagnosed invasive cancer of the colon (ICD-O-1 T-153) and rectum (ICD-O-1 T-154) diagnosed between January 1, 1992 and December 31, 2007 were included in this analysis. Tumors that penetrated into the submucosa or beyond were considered invasive cancer.

Tumors of the anal canal (154.2) and anus unspecified (154.3) were excluded. Patients were also excluded if their tumor was diagnosed at autopsy $(n=11)$. We further restricted the analysis to adenocarcinomas (ICD-O-1 M8140/3), mucinous adenocarcinomas (ICD-O-1 M-8480/3) and signet ring cell carcinoma (ICD-O-1 M-8490/3).

The beginning of follow-up was the date of histopathological diagnosis. The events of interest were death due to any cause (overall survival) and death due to CRC (causespecific survival). Patients alive at the end of the followup (December 31, 2008), those lost to follow-up, and those who died of causes other than CRC cancer were censored either at the last contact or at death.

\section{Study variables}

The demographic variables examined included age at diagnosis, categorized in three groups (0-49, 50-75 and > 75 years), sex, and year of diagnosis, grouped in three periods (1992-1997, 1998-2002 and 2003-2007). Tumor characteristics included anatomical site (right colon: from cecum to transverse; left colon: from the splenic flexure to sigmoid colon; colon NOS -not otherwise specified-; and rectum). Patients with synchronous tumors were classified according to the lesion at the most advanced stage. The stage grouping at presentation was classified according to the version of the pathological tumor-node-metastasis (TNM) classification that was used in the year of diagnosis. For patients offered neoadjuvant therapy and those who did not undergo surgery, staging was based on the TNM clinical classification. Finally, patients were classified according to the type of hospital admission (elective or emergency).

\section{Statistical analysis}

The 5- and 10-year overall and specific survival rates were estimated using the Kaplan-Meier method. Survival curves were estimated using the Kaplan-Meier product limit method and the differences between the categories of each variable were assessed using the log-rank test. The relationship between specific survival time and covariates of interest (age, sex, stage, anatomical site, period of diagnosis, histological grade and type of hospital admission) was assessed by Cox regression models. To calculate overall and CRC-specific survival, Stata statistical software (version 8.0) was used.

This study was performed in accordance with the ethical standards of the Declaration of Helsinki and complied with the legal regulations on data confidentiality (Ley Orgánica 15/1999, de 13 de diciembre, de Protección de Datos de Carácter Personal). It was also approved by the Ethics Committee of Parc de Salut Mar.

\section{RESULTS}

We identified 2,080 newly diagnosed invasive CRC cases diagnosed between 1992-2007. Table I shows the characteristics of the study cohort. The median age at diagnosis was 72 years (interquartile range 64-79 years) and $58.5 \%$ were male. The $\mathrm{CRC}$ sites were as follows: right colon $25.0 \%$, left colon $36.1 \%$, colon $N O S 5.9 \%$, and rectum $33.0 \%$. Almost half of the cases were diagnosed in stage I or II (47.8\%). The most common histological type was adenocarcinoma $(93.7 \%)$, followed by mucinous adenocarcinoma $(5.7 \%)$ and signet ring cell carcinoma $(0.6 \%)$. The percentage of patients aged 75 or more at diagnosis increased over time. We observed a decline in patients with tumors located in the rectum and in those admitted through the emergency department. Colon cancer, as well as rectal cancer treatment, changed over time (i.e. the use of radiotherapy plus chemotherapy followed by surgery for rectal cancer increased from $1.2 \%$ in the first period to $37.5 \%$ in the last period) (data not shown). Adjuvant chemotherapy was administrated to $62.3 \%$ of patients with colon cancer and to $31.5 \%$ of those with rectum cancer.

By the end of follow-up, 1,225 patients had died: 838 deaths $(68.4 \%)$ were due specifically to colorectal neoplasm and $12(0.6 \%)$ were due to unknown causes. Around $84 \%$ of surviving patients had been visited at some time during 2008.

The 5- and 10-year overall survival rates for the entire cohort were $44.0 \%$ (95\%CI 41.6-46.3) and $28.8 \%$ (95\%CI 26.2-31.4), respectively (Table II). CRC-specific survival 
Table I. Distribution of colorectal cancer cases by period of diagnosis, $\mathbf{n}(\%)$

\begin{tabular}{|c|c|c|c|c|c|c|c|c|}
\hline \multirow{3}{*}{$\begin{array}{l}\text { Characteristic } \\
\text { Number of cases }\end{array}$} & \multirow[t]{3}{*}{ Total } & \multirow{3}{*}{$\begin{array}{r}\% \\
2,080\end{array}$} & \multicolumn{6}{|c|}{ Period of diagnosis } \\
\hline & & & \multicolumn{2}{|c|}{ 1992-1997 } & \multicolumn{2}{|c|}{$1998-2002$} & \multicolumn{2}{|c|}{$2003-2007$} \\
\hline & & & 633 & $(30.4)$ & 636 & $(30.6)$ & 811 & (39.0) \\
\hline \multicolumn{9}{|l|}{ Sex } \\
\hline Female & 863 & $(41.5)$ & 267 & $(42.2)$ & 279 & $(43.9)$ & 317 & (39.1) \\
\hline Male & 1217 & $(58.5)$ & 366 & $(57.8)$ & 357 & $(56.1)$ & 494 & $(60.9)$ \\
\hline \multicolumn{9}{|l|}{ Age at diagnosis (years) } \\
\hline$<50$ & 109 & $(5.2)$ & 29 & $(4.6)$ & 39 & $(6.1)$ & 41 & $(5.1)$ \\
\hline $50-75$ & 1,199 & $(57.6)$ & 408 & $(64.5)$ & 339 & $(53.3)$ & 452 & $(55.7)$ \\
\hline$>75$ & 772 & $(37.1)$ & 196 & $(31.0)$ & 258 & $(40.6)$ & 318 & $(39.2)$ \\
\hline \multicolumn{9}{|l|}{ Site } \\
\hline Right colon & 521 & $(25.0)$ & 124 & $(19.6)$ & 167 & $(26.3)$ & 230 & $(28.4)$ \\
\hline Left colon & 750 & $(36.1)$ & 188 & $(29.7)$ & 238 & (37.4) & 324 & (39.9) \\
\hline Colon, NOS & 122 & $(5.9)$ & 68 & $(10.7)$ & 32 & $(5.0)$ & 22 & $(2.7)$ \\
\hline Rectum & 687 & $(33.0)$ & 253 & $(40.0)$ & 199 & (31.3) & 235 & $(29.0)$ \\
\hline \multicolumn{9}{|l|}{ Stage grouping at diagnosis } \\
\hline 1 & 321 & $(15.4)$ & 106 & $(16.7)$ & 81 & $(12.7)$ & 134 & $(16.5)$ \\
\hline$\|$ & 674 & (32.4) & 216 & (34.1) & 222 & (34.9) & 236 & $(29.1)$ \\
\hline III & 581 & (27.9) & 167 & $(26.4)$ & 165 & $(25.9)$ & 249 & $(30.7)$ \\
\hline IV & 426 & (20.5) & 122 & (19.3) & 134 & $(21.1)$ & 170 & $(21.0)$ \\
\hline Unknown & 78 & $(3.8)$ & 22 & $(3.5)$ & 34 & $(5.3)$ & 22 & $(2.7)$ \\
\hline \multicolumn{9}{|l|}{ Histological grade } \\
\hline । & 104 & $(5.0)$ & 26 & $(4.1)$ & 26 & $(4.10)$ & 52 & (6.4) \\
\hline$\|$ & 1,691 & $(81.3)$ & 535 & $(84.5)$ & 528 & (83.0) & 628 & $(77.4)$ \\
\hline III/IV & 167 & $(8.0)$ & 30 & $(4.7)$ & 50 & $(7.9)$ & 87 & $(10.7)$ \\
\hline Unknown or not evaluated & 118 & $(5.7)$ & 42 & $(6.6)$ & 32 & $(5.0)$ & 44 & $(5.4)$ \\
\hline \multicolumn{9}{|l|}{ Type of hospital admission } \\
\hline Elective & 1,047 & $(50.3)$ & 262 & $(41.4)$ & 300 & $(47.2)$ & 485 & $(59.8)$ \\
\hline Emergency & 1,033 & $(49.7)$ & 371 & $(58.6)$ & 336 & $(52.8)$ & 326 & $(40.2)$ \\
\hline
\end{tabular}

Colon, NOS = colon, not otherwise specified.

rates were higher: $55.5 \%$ (95\% CI 53.0-57.9) at 5-years and $48.5 \%$ (95\% CI 45.6-51.3) at 10-years. The median cancerspecific survival was 7.7 years (95\%CI 6.38-12.01 years) (Fig. 1). The 5-year specific survival rate showed an absolute increase of 7 points between the first period (19921997) and the third (2003-2007). However, the survival rate was slightly lower in the second period (1998-2002) (Table II). The lowest 5-year CRC-specific survival was observed among males $(54.0 \%)$, patients aged $>75$ years $(48.4 \%)$, tumors located in the rectum $(54.7 \%)$, stage IV tumors $(5.5 \%)$, poorly differentiated/undifferentiated tumors $(31.8 \%)$ and patients admitted through the emergency department $(46.1 \%)$.

Multivariate analysis showed that the factors leading to a less favorable prognosis were diagnosis in 1992-1997 (HR 1.43; 95\%CI 1.20-1.70), male sex (HR 1.21; 95\%CI 1.05-1.39), age $>75$ years (HR 1.97; 95\%CI 1.41-2.75), neoplasms located in the rectum (HR 1.33; 95\%CI 1.101.61), stage IV tumors (HR 18.54; 95\%CI 13.28-25.89), poorly differentiated/undifferentiated tumors (HR 1.80; 95\%CI 1.17-2.77), and admission through the emergency department (HR 1.52; 95\%CI 1.32-1.75) (data not shown).

\section{DISCUSSION}

Five- and 10-year CRC-specific survival rates were 55.5 and $48.5 \%$, respectively. Various CRC characteristics changed over the study period and 5-year survival improved in the last period. Moreover, various factors independently associated with excess risk of death were identified.

The results show that both the 5-year overall and CRCspecific survival were similar to those described by previous studies. Galceran et al. (3) reported that the overall and rel- 
Table II. Five- and 10-year overall and colorectal cancer-specific survival'

\begin{tabular}{|c|c|c|c|c|c|c|c|c|}
\hline \multirow{3}{*}{$\begin{array}{l}\text { Characteristic } \\
\text { Overall }\end{array}$} & \multicolumn{4}{|c|}{ Overall survival $(95 \%$ Cl) } & \multicolumn{4}{|c|}{ Specific survival $(95 \%$ Cl) } \\
\hline & \multicolumn{2}{|c|}{ 5-year } & \multicolumn{2}{|c|}{ 10-year } & \multicolumn{2}{|c|}{ 5-year } & \multicolumn{2}{|c|}{ 10-year } \\
\hline & 44.0 & $41.6-46.3$ & 28.8 & $26.2-31.4$ & 55.5 & $53.9-57.9$ & 48.5 & $45.6-51.3$ \\
\hline \multicolumn{9}{|c|}{ Period of diagnosis } \\
\hline $2003-2007$ & 48.6 & $43.5-53.5$ & \multicolumn{2}{|c|}{-} & 60.4 & $55.4-65.0$ & \multicolumn{2}{|c|}{-} \\
\hline $1998-2002$ & 39.8 & $35.9-43.6$ & 27.8 & $23.9-31.8$ & 52.0 & $47.8-56.2$ & 47.9 & $43.5-52.2$ \\
\hline 1992-1997 & 42.7 & $38.8-46.6$ & 27.4 & $23.9-31.0$ & 53.4 & $49.2-57.4$ & 45.7 & $41.3-49.9$ \\
\hline \multicolumn{9}{|l|}{ Sex } \\
\hline Female & 47.4 & $43.8-51.0$ & 34.8 & $30.7-38.9$ & 57.4 & $53.6-61.0$ & 52.3 & 48.1-56.4 \\
\hline Male & 41.4 & $38.3-44.5$ & 24.4 & $21.2-27.8$ & 54.0 & $50.6-57.1$ & 45.4 & $41.5-49.2$ \\
\hline \multicolumn{9}{|c|}{ Age at diagnosis (years) } \\
\hline$<50$ & 58.5 & $47.6-67.9$ & 55.2 & $44.0-65.0$ & 61.6 & $50.8-70.7$ & 58.1 & $46.8-67.8$ \\
\hline $50-75$ & 51.2 & $48.0-54.2$ & 36.0 & $32.5-39.4$ & 59.3 & $56.1-62.4$ & 51.6 & $48.0-55.1$ \\
\hline$>75$ & 30.3 & $26.7-34.0$ & 12.8 & $9.5-16.7$ & 48.4 & $44.2-52.6$ & 41.7 & $35.9-47.3$ \\
\hline \multicolumn{9}{|l|}{ Site } \\
\hline Right colon & 45.7 & $41.0-50.4$ & 33.0 & $27.9-38.3$ & 59.1 & $54.1-63.7$ & 54.9 & $49.5-60.0$ \\
\hline Left colon & 44.8 & $40.8-48.8$ & 29.3 & 24.9-33.9 & 55.8 & $51.6-59.8$ & 49.8 & $44.5-54.2$ \\
\hline Colon NOS & 32.9 & $24.2-41.8$ & 20.2 & $12.8-28.8$ & 43.0 & $33.2-52.4$ & 36.4 & $26.4-46.5$ \\
\hline Rectum & 43.7 & $39.6-47.7$ & 27.2 & $22.9-31.6$ & 54.7 & $50.3-58.9$ & 45.6 & $40.5-50.4$ \\
\hline \multicolumn{9}{|c|}{ Stage grouping at diagnosis } \\
\hline 1 & 71.2 & $65.3-76.2$ & 48.4 & $40.5-55.9$ & 87.9 & 83.1-91.4 & 80.7 & $73.1-86.4$ \\
\hline$\|$ & 56.4 & $52.2-60.4$ & 39.1 & $34.4-43.8$ & 71.0 & $66.9-74.7$ & 63.8 & $58.9-68.3$ \\
\hline III & 45.0 & $40.3-49.5$ & 25.0 & $20.1-30.3$ & 55.9 & $50.9-60.6$ & 44.0 & $37.9-49.9$ \\
\hline IV & 4.5 & $2.5-7.4$ & \multicolumn{2}{|r|}{ - } & 5.5 & $3.1-9.0$ & \multicolumn{2}{|c|}{-} \\
\hline Unknown & 20.9 & $12.2-31.1$ & \multicolumn{2}{|c|}{-} & 36.6 & $23.8-49.4$ & \multicolumn{2}{|c|}{-} \\
\hline \multicolumn{9}{|c|}{ Histological grade } \\
\hline I & 48.1 & $37.2-58.3$ & 34.6 & $22.7-46.8$ & 68.8 & $57.1-77.9$ & 68.8 & $57.1-77.9$ \\
\hline$\|$ & 46.3 & $43.6-48.9$ & 29.8 & $26.9-32.7$ & 58.8 & $55.0-60.4$ & 49.7 & $46.4-52.8$ \\
\hline III/IV & 24.9 & $17.0-33.6$ & \multicolumn{2}{|c|}{-} & 31.8 & $22.8-41.2$ & \multicolumn{2}{|r|}{-} \\
\hline Unknown & 32.0 & $23.5-40.9$ & 23.5 & $14.9-33.4$ & 42.7 & $32.7-51.4$ & 40.5 & $30.9-50.0$ \\
\hline \multicolumn{9}{|c|}{ Type of hospital admission } \\
\hline Elective & 53.1 & $49.6-56.5$ & 34.8 & $30.6-38.3$ & 64.9 & $61.1-67.9$ & 55.0 & $50.6-69.2$ \\
\hline Emergency & 35.0 & $31.9-38.1$ & 22.9 & $19.9-26.1$ & 46.1 & $42.6-49.5$ & 41.5 & $37.7-45.2$ \\
\hline
\end{tabular}

'Results expressed in percentages. Colon, NOS = colon, not otherwise specified.

ative survival rates in Catalonia in 1995-1999 were 43.8 and $52.1 \%$, respectively. According to Chirlaque et al. (10), the 5-year relative survival rate for CCR in Spain (considering seven Spanish geographical areas) during the same period was $52 \%$. The highest 5-year relative survival rates for colon cancer during the period 1995-1999 were observed in the population-based cancer registries of Murcia $(59.6 \%, 95 \%$ CI 56.5-62.6) and Girona $(57.9 \%, 95 \% \mathrm{CI}$ 54.3-61.4) while the lowest rates were in Albacete 51.5\% (95\%CI 45.6-57.0) and Granada (50.5\%, 95\% CI 46.6-54.4). Regarding rectum cancer, the highest 5-year relative survival rates were 54.4\% (95\%CI 50.5-58.2) in Murcia and
$53.3 \%$ (95\% CI 48.4-57.9) in Navarre. Contrarily, the lowest 5-year relative survival rates for rectum cancer were $45.9 \%$ (95\% CI 40.6-51.0) in Granada and 43.6\% (95\% CI 36.8-50.2) in Albacete (10).

In Europe during the period 1997-1999, 5-year relative survival rate was $58.8 \%$ in Northern countries (Finland, Iceland, Norway and Sweden), 50.5\% in United Kingdom and $57.4 \%$ in central countries (Germany, Austria, Switzerland, France and Netherland) (2).

Studies reporting 10-year survival rates are scarce. Verdecchia et al. (11) found a difference of less than 5 points when comparing 5- and 10-year relative survival rates. This 
finding indicates that deaths occur primarily within 5 years of diagnosis. Our study found a similar difference ( 7 points) and the 10-year relative survival rates $(46 \%$ in the first period and $48 \%$ in the second) were higher than those observed by Mitry et al. $(12,13)$ in England and Wales $(35 \%-40 \%$ in 1991-1995). The modest improvement in survival over the study period is consistent with the results of other studies performed in Catalonia (3) and other European countries $(2,12,13)$. This phenomenon has been attributed to improvements in diagnosis and treatment in more recent periods $(3,12,13)$. We observed that the proportion of cancers in stages I-II slightly declined from the first period (50.8\%) to the last $(45.6 \%)$. Therefore, earlier cancer detection could not be considered as the main reason for the improved survival in our setting. This result was expected, as population-based CRC screening program only started recently (2009) in Catalonia and during the study period screening

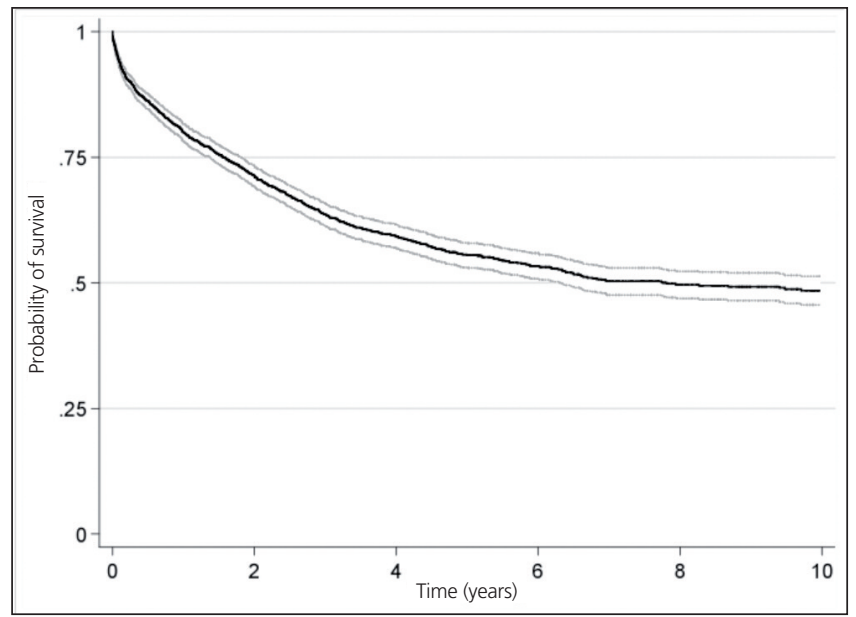

Fig. 1. Kaplan-Meier curve for colorectal cancer-specific survival.

Table III. Crude and adjusted hazard ratios (HR) for colorectal cancer-specific mortality

\begin{tabular}{|c|c|c|c|c|c|c|}
\hline \multirow[t]{2}{*}{ Characteristic } & \multirow[t]{2}{*}{ Total } & \multirow[t]{2}{*}{ Events } & \multicolumn{2}{|c|}{ Univariate } & \multicolumn{2}{|c|}{ Multivariate* } \\
\hline & & & $H R$ & $95 \% \mathrm{Cl}$ & $H R$ & $95 \% \mathrm{Cl}$ \\
\hline \multicolumn{7}{|l|}{ Period of diagnosis } \\
\hline $2003-2007$ & 811 & 240 & 1.00 & ref. & 1.00 & ref. \\
\hline 1998-2002 & 636 & 285 & 1.29 & $1.09-1.54$ & 1.26 & $1.06-1.50$ \\
\hline 1992-1997 & 633 & 313 & 1.29 & $1.09-1.53$ & 1.43 & $1.20-1.70$ \\
\hline \multicolumn{7}{|l|}{ Sex } \\
\hline Female & 863 & 336 & 1.00 & ref. & 1.00 & ref. \\
\hline Male & 1,217 & 502 & 1.13 & $0.98-1.30$ & 1.21 & $1.05-1.39$ \\
\hline \multicolumn{7}{|l|}{ Age at diagnosis (years) } \\
\hline$<50$ & 109 & 39 & 1.00 & ref. & 1.00 & ref. \\
\hline $50-75$ & 1,199 & 460 & 1.06 & $0.76-1.47$ & 1.05 & $0.75-1.45$ \\
\hline$>75$ & 772 & 339 & 1.66 & $1.20-2.33$ & 1.97 & $1.41-2.75$ \\
\hline \multicolumn{7}{|l|}{ Site } \\
\hline Right colon & 521 & 189 & 1.00 & ref. & 1.00 & ref. \\
\hline Left colon & 750 & 297 & 1.07 & $0.89-1.28$ & 1.15 & $0.95-1.39$ \\
\hline Colon NOS & 122 & 66 & 1.75 & $1.33-2.33$ & 1.71 & $1.28-2.29$ \\
\hline Rectum & 687 & 286 & 1.09 & $0.90-1.31$ & 1.33 & $1.10-1.61$ \\
\hline \multicolumn{7}{|l|}{ Stage grouping at diagnosis } \\
\hline I & 321 & 41 & 1.00 & ref. & 1.00 & ref. \\
\hline$\|$ & 674 & 184 & 2.38 & $1.70-3.33$ & 2.17 & $1.54-3.05$ \\
\hline III & 581 & 225 & 3.87 & $2.77-5.40$ & 3.77 & $2.70-5.28$ \\
\hline IV & 426 & 348 & 18.63 & $13.41-25.89$ & 18.54 & $13.28-25.89$ \\
\hline Unknown & 78 & 40 & 8.94 & $5.78-13.83$ & 7.37 & $4.75-11.45$ \\
\hline \multicolumn{7}{|l|}{ Histological grade } \\
\hline I & 104 & 27 & 1.00 & ref. & 1.00 & ref. \\
\hline$\|$ & 1,691 & 651 & 1.48 & $1.00-2.17$ & 1.12 & $0.76-1.64$ \\
\hline III/IV & 167 & 95 & 3.52 & $2.29-5.40$ & 1.80 & $1.17-2.77$ \\
\hline Unknown or not evaluated & 118 & 65 & 3.00 & $1.92-4.71$ & 1.90 & $1.20-2.99$ \\
\hline \multicolumn{7}{|l|}{ Type of hospital admission } \\
\hline Elective & 1,047 & 337 & 1.00 & ref. & 1.00 & ref. \\
\hline Emergency & 1,033 & 501 & 1.81 & $1.57-2.08$ & 1.52 & $1.32-1.75$ \\
\hline
\end{tabular}

*Adjusted by sex, age group, stage at diagnosis, period of diagnosis, histological grade and type of hospital admission. Colon, NOS = colon, not otherwise specified. 
was purely opportunistic. The improved survival could have been influenced by changes in treatment patterns (i.e. an increasing proportion of colon cancer cases were treated with surgery followed by chemotherapy while cases of rectal cancer were treated by the combination of radiotherapy, chemotherapy and surgery).

In agreement with other studies (4,5), survival rates were statistically significantly higher in women. This association has been attributed to many underlying factors, such as access to care, sex-specific co-morbidites, treatment disparities and hormonal status. Like previous studies $(4,6)$, our data also showed that survival was poorer in the elderly than in younger patients.

As an inherent consequence of the methods used to calculate overall and cancer-specific survival rates, our results also show a gradient in the difference between the two methods: the older the age group, the greater the difference in the results of the two methods.

The CONCORD study observed that in most countries, survival was better in patients with colon cancers than in those with rectal cancers (5). In Spain (10), the 5-year relative survival rates for colon cancer of seven populationbased cancer registries were higher than those for rectum cancer.

The association found between an excess risk of death and some clinical factors is consistent with the results of previous studies. Advanced stage at diagnosis (6), undifferentiated/poorly differentiated tumors (4), and admission through the emergency department (9) are factors that are well known and described in the literature.

To our knowledge, this is one of the largest studies ever performed in Spain that estimates CRC-specific survival and provides direct evidence that clinical characteristics are major determinants of survival. Other advantages are the long follow-up and the low percentage of cases with an unknown cause of death. However, this study has some limitations. First, the information source was a single institution and thus the cohort studied cannot be considered as representative of all CRC patients in Barcelona. However, referral selection bias is unlikely to have occurred, as our center is well coordinated with its catchment area. Secondly, our registry lacks data on some factors, such as patients' medical co-morbidities and socioeconomic status, which have been associated with survival (8).

In conclusion, the overall and specific survival rates of patients with CRC improved from 1992 to 2007. The most important factors associated with mortality were older age and advanced stage at diagnosis. As no changes in stage distribution or age of diagnosis were observed during this period, the improvement in survival rate can be attributed to more effective treatment. The main challenge for the future is to detect cases in earlier stages with the introduction of the population-based CRC screening program in Spain. Further studies will be needed to determine the impact of these programs.

\section{ACKNOWLEDGMENTS}

We are grateful to Àngels Hospital, Mercè-Piracés and Ramon Clèries. This work was supported by a grant from the Fondo de Investigación Sanitaria, ISCIII, Spain (FIS-FEDER PI07/90861) CIBER Epidemiología y Salud Pública (CIBERESP), and FEDER RTICC (RD06/0020/0109), Spain.

\section{REFERENCES}

1. Borràs JM, Pareja L, Peris M, Espinàs JA. Análisis de la incidencia, la supervivencia y la mortalidad según las principales localizaciones tumorales, 1985-2019: cáncer colorrectal. Med Clin (Barc) 2008;131(Supl. 1):S58-S62.

2. Brenner H, Bouvier AM, Foschi R, Hackl M, Larsen IK, Lemmens V, et al; EUROCARE Working Group. Progress in colorectal cancer survival in Europe from the late 1980s to the early 21st century: the EUROCARE study. Int J Cancer 2012;131:1649-58.

3. Galceran J, Puigdefàbregas A, Ribas G, Izquierdo A, Pareja L, Marcos-Gragera R. Evolución de la supervivencia del cáncer en Cataluña y comparación con Europa. Med Clin (Barc) 2008;131(Supl. 1):S19S24.

4. Weiss JM, Pfau PR, O'Connor ES, King J, LoConte N, Kennedy G, et al. Mortality by stage for right- versus left-sided colon cancer: analysis of surveillance, epidemiology, and end results - Medicare data. J Clin Oncol 2011;29:4401-9.

5. Coleman M, Quaresma M, Berrino F, Lutz JM, De Angelis R, Capocaccia $\mathrm{R}$, et al. Cancer survival in five continents: a worldwide population-based study (CONCORD). Lancet Oncol 2008;9:730-56.

6. Nedrebø B, Søreide K, Eriksen M, Dørum L, Kvaløy J, Søreide J, et al. Survival effect of implementing national treatment strategies for curatively resected colonic and rectal cancer. J Surg 2011;98:716-23.

7. Quan D, Gallinger S, Nhan C, Auer RA, Biagi JJ, Fletcher GG, et al. The role of liver resection for colorectal cancer metastases in an era of multimodality treatment: a systematic review. Surgery 2012;151:86070 .

8. Jørgensen TL, Hallas J, Friis S, Herrstedt J. Comorbidity in elderly cancer patients in relation to overall and cancer-specific mortality. $\mathrm{Br}$ J Cancer 2012;106:1353-60.

9. Porta M, Fernandez E, Belloc J, Malats N, Gallén M, Alonso J. Emergency admission for cancer: a matter of survival? Br J Cancer 1998;77:477-84.

10. Chirlaque MD, Salmerón D, Ardanaz E, Galceran J, Martínez R, Marcos-Gragera R, et al. Cancer survival in Spain: estimate for nine major cancers. Ann Oncol 2010;21(Supl. 3):iii21-9.

11. Verdecchia A, Francisci S, Brenner H, Gatta G, Micheli A, Mangone L, et al. Recent cancer survival in Europe: a 2000-02 period analysis of EUROCARE-4 data. Lancet Oncol 2007;8:784-96.

12. Mitry E, Rachet B, Quinn M, Cooper N, Coleman MP. Survival from cancer of the colon in England and Wales up to 2001. Br J Cancer 2008;99(Supl. 1):S26-9.

13. Mitry E, Rachet B, Quinn M, Cooper N, Coleman MP. Survival from cancer of the rectum in England and Wales up to 2001. Br J Cancer 2008;99(Supl. 1):S30-2. 